Here I focus on the geomorphic evidence for plume-related uplift in Africa and on the more general question of the use of drainage patterns in the reconstruction of surface uplift histories.

Cox argues that drainage patterns indicative of topographic doming can be preserved for up to $200 \mathrm{Myr}$, and that they can therefore provide a basis for testing uplift models. Although he acknowledges cases in which initial drainage systems have been modified significantly, Cox's key point is that rifted domal uplifts create half-radial drainage patterns which can be preserved sufficiently to allow the identification of gross palaeotopography. The development of such drainage patterns in response to rifting has been pointed out previously ${ }^{3.4}$ but, because the primary fluvial systems formed consist of consequent (dip) streams, the resulting halfradial drainage patterns are essentially a reflection of gross topography. It is topography, therefore, that should be the focus of investigation, with fluvial systems being analysed where drainage patterns are anomalous.

One of the proposed plume-related uplifts considered by Cox is the Cape Angola high. It is clear that, even on a broad scale, the morphology of this region consists of two, rather than one, major areas of elevated topography (the Bie Plateau in the north, and the high terrain in central Namibia culminating in the Auas Mountains in the south) which are separated by the Etosha Basin, where the elevation falls to below $1,200 \mathrm{~m}$. Drainage patterns reflect this topography, although Cox points to the anomalous course of the westward-draining Orange River across the extreme southern flank of this hypothesized zone of plume-related uplift. This river course, and the incision of the Orange below the Augrabies Falls, is intepreted by Cox as evidence of drainage antecedence, but there is a significant body of literature extending back to early this century (see ref. 5 for review) demonstrating - on the basis of geomorphic, stratigraphic, sedimentological, palaeontological and zoological evidence - that the palaeo-Orange has shifted its outlet significantly since the formation of the South Atlantic. Capture of dome-flank drainage by rift-related river systems can account for the present-day incision of the lower Orange, as also can concurrent local surface uplift resulting from a flexural

\section{Corrections}

- The title of the Scientific Correspondence, P. A. Kitchin et al. Nature 344, 201 (1990) should read: "Avoidance of PCR false positives".

- Line 67 of M. Super et al. Nature 344, 113 (1990) should read: "With CF, 100,000 pregnancies would require 104 amniocenteses which would detect 26 of 40 cases (arithmetic available on request)."

isostatic response to denudational unloading focused in the vicinity of the Great Escarpment. Cox's discussion of the river patterns in the vicinity of the lower Zambezi similarly ignores well substantiated major changes in the drainage of this area during the Late Cenozoic ${ }^{6}$.

Cox also attempts to reconcile the single uplift event suggested by the plume model with what he interprets as firm evidence of episodic uplift and denudation in the form of cyclic erosion surfaces. Such reconciliation may, however, be unnecessary, because the interpretation of the landscapes of southern Africa (and other Gondwana terrains) in terms of episodic surface uplift and denudation has been strongly challenged ${ }^{7.8}$, both on the basis of the techniques used to correlate erosion surfaces and in terms of the evident structural control of many such surfaces. Moreover, fission-track studies have indicated significant depths of post-rifting erosion extending far inland along a

\title{
Wasps fail to make distinctions
}

SIR-A recent experiment ${ }^{1}$ showed that worker honeybees can discriminate degrees of relatedness among their female colony mates and that they preferentially aid closer relatives. If this ability were general, our view of the organization of colonies of social insects would have to be radically revised. Instead of working together for the reproductive good of the colony, workers could each pursue partially independent reproductive strategies, each trying to aid its closest relatives. But we have data indicating that females of the paper wasp, Polistes annularis, either do not possess this ability or do not use it effectively.

In the spring of 1988, we collected recently-founded colonies of $P$. annularis at a site at which we had marked individuals with colony-specific two-colour paint marks the preceding autumn. Of those individuals that retained both colour marks in the spring, $98 \%$ of colony-mate dyads shared the same colour combination, confirming the previously known fact $^{2}$ that spring associations consist of females reared on the same natal nest the previous autumn. But when at least two spring nests arise from the same autumn nest, females are presented with a choice: do they then discriminate degrees of relatedness and prefer to join a subset of natal nestmates to whom they are most closely related?

We have studied females given a clear opportunity to choose among at least two sets of natal nestmates from 29 fall colonies that gave rise to at least two nearby spring colonies. (Those further than $5 \mathrm{~m}$ from their natal nest were excluded.) We estimated the relatedness ${ }^{3}$ of the 222 females retaining both of their identifying marks by starch gel electrophoresis of number of passive margins, including southwest Africa, and these cast doubt on existing denudation chronologies based on erosion surface correlation. Such thermochronological investigations arguably provide the most promising basis for unravelling the key problem of the morphological evolution of passive margins.

\section{A. SUMMERFIELD}

Macrogeomorphology Research Group,

Department of Geography,

University of Edinburgh,

Edinburgh EH8 9XP, UK

1. Cox, K.G. Nature 342, 873-877 (1989).

2. White, R.S. \& McKenzie, D.P. J. geophys. Res. 94, 7685 7730 (1989)

3. Summerfield, M.A. Area 13, 3-8 (1981)

4. Veevers, J.J. J. Geol. 89, 57-82 (1981)

5 . Dingle, R.V. \& Hendey, Q. B. Mar. Geol. 56, 13-26 (1984)

6. Thomas, D.S.G. \& Shaw, P.A. J. Afr. Earth Sci. 7, 611-618 (1988).

7. De Swardt, A.M.J. \& Bennet, G. Trans. geol. Soc. S. Afr. 77, 309-322 (1974).

8. Summerfield, M.A. in Tectonic Geomorphology (eds Morisawa, M. \& Hack, J.T.) 27-51 (Allen and Unwin. Boston, 1985)

proteins. What we find is that the average relatedness to spring colony-mates $\left(r_{1}=\right.$ 0.469 ) is indistinguishable from that to other females from the same autumn nest $\left(r_{2}=0.452\right)$, suggesting that no preference is expressed. Of course, some degree of discrimination could be missed because of sampling error, but the $95 \%$ confidence interval for the difference $r_{1}-r_{2}$ runs from -0.066 to +0.099 , showing that we can exclude any discrimination larger than 0.1 .

Either $P$. annularis females lack the ability to perform such discrimination, or they fail to use it effectively in a natural situation where it would be highly advantageous. The choice has crucial consequences for inclusive fitness because most females $(74 \%)$ end up being subordinates who reproduce indirectly by aiding the dominant egg-layer ${ }^{2}$. Since average relatedness among fall nestmates is rather low, aiding randomly chosen natal nestmates would make a small contribution to inclusive fitness. At least some super-sisters $(r=3 / 4)$ are likely to be available, and preferentially helping them would be a far more effective genetic strategy.

DAVID C. QUELLER

COLIN R. HUGHES

JOANE. STRASSMANN

Department of Ecology and

Evolutionary Biology,

Rice University,

PO Box 1892,

Houston, Texas 77251 ,

USA

1. Page, R.E. Jr., Robinson, G.E. \& Fondrk, M.K. Nature $\mathbf{3 3 8}$,
$576-579(1989)$.
2. Strassmann, J.E. Fla. Entomol. 64, $74-88$ (1981).
3. Queller, D.C. \& Goodnight, K.F. Evolution 43, 258-275 (1989).

NATURE · VOL $344 \cdot 29$ MARCH 1990 